\title{
Schwann Cell Caveolin-1 Expression Increases During Myelination and Decreases After Axotomy
}

\author{
DANIEL D. MIKOL, ${ }^{1 *}$ STEVEN S. SCHERER, ${ }^{2}$ SARA J. DUCKETT, ${ }^{1}$ \\ HOYLOND L. HONG, ${ }^{1}$ AND EVA L. FELDMAN ${ }^{1}$ \\ ${ }^{1}$ Department of Neurology, University of Michigan, Ann Arbor, Michigan \\ ${ }^{2}$ Department of Neurology, University of Pennsylvania, Philadelphia, Pennsylvania
}

\begin{abstract}
KEY WORDS Caveolae; cholesterol; differentiation; myelin; nerve
\end{abstract}
\begin{abstract}
The caveolins are a family of related proteins that form the structural framework of caveolae. They have been implicated in the regulation of signal transduction, cell cycle control, and cellular transport processes, particularly cholesterol trafficking. Caveolin-1 is expressed by a variety of cell types, including Schwann cells, although its expression is greatest in differentiated cell types, such as endothelial cells and adipocytes. In the present work, we characterize caveolin-1 expression both during rat sciatic nerve development and after axotomy. Schwann cells express little caveolin-1 on postnatal days 1 and 6. By P30, myelinating Schwann cells express caveolin-1, which is localized in the outer/abaxonal myelin membranes as well as intracellularly. After axotomy, Schwann cell caveolin-1 expression in the distal nerve stump decreases as Schwann cells revert to a premyelinating (p75-positive) phenotype; residual caveolin-1 within the nerve largely localizes to myelin debris and infiltrating macrophages. We speculate that caveolin-1 plays a role in the biology of myelinating Schwann cells. GLIA 38:191-199, $2002 . \quad$ @ 2002 Wiley-Liss, Inc.
\end{abstract}

\section{INTRODUCTION}

During development, Schwann cells (SC) are regulated by axon-derived signals. In embryonic nerve, SC precursors are first apparent at E14-15, giving rise to S-100-positive immature/premyelinating SC at E1517; postnatally, these SC will give rise to myelinating and nonmyelinating SC (Jessen and Mirsky, 1991). Premyelinating SC can proliferate and are distinguished by markers such as the low-affinity nerve growth factor receptor, or p75 (Jessen and Mirsky, 1999a). As SC establish contact with large-diameter axons, they withdraw from the cell cycle and myelin synthesis ensues, with the first myelin wraps forming during the initial $24 \mathrm{~h}$ (Jessen and Mirsky, 1991); this stage is characterized by the expression of myelin proteins such as $\mathrm{P}_{0}$ and myelin-associated glycoprotein (MAG) (Jessen et al., 1991; Webster, 1993) and the loss of p75 expression (Taniuchi et al., 1986). After nerve transection, previously myelinating SC cease to express $\mathrm{P}_{0}$ and MAG and appear to revert to a dedifferentiated, premyelinating phenotype (Mirsky and Jes- sen, 1990; S. Scherer and Asbury, 1993; S. Scherer and Salzer, 1996; Jessen and Mirsky, 1999b).

Caveolae are plasma membrane microdomains enriched in cholesterol, glycosphingolipids, signaling molecules, and the caveolins. Caveolins not only provide the structural framework of caveolae (Lisanti et al., 1993); they also regulate multiple signal transduction processes (Okamoto et al., 1998). Of the known caveolins, caveolin-1 has been most studied (Glenney and Soppet, 1992; P. Scherer et al., 1996; Tang et al., 1996). There are two caveolin- 1 isoforms, $24 \mathrm{kDa}(\alpha)$ and 21

Grant sponsor: National Institutes of Health, Grant number: NS01928; Grant number:NS08075; Grant number:NS37100; Grant number:NS36778; Grant number:NS38849; Grant sponsor: Juvenile Diabetes Research Foundation; Grant sponsor: American Diabetes Association.

*Correspondence to: Daniel D. Mikol, Department of Neurology, University of Michigan, 200 Zina Pitcher Place, 4414 Kresge III, Ann Arbor, MI 48109. E-mail: dmiko@umich.edu

Received 6 November 2001; Accepted 15 January 2002

DOI 10.1002/glia.10063 
$\mathrm{kDa}(\beta)$, generated from two separate transcripts (Kogo and Fujimoto, 2000). Caveolin-1 binds to itself to form a multimeric complex (Fra et al., 1995), serving as a scaffold for a variety of signaling molecules including growth factor receptors and downstream signaling molecules (Sargiacomo et al., 1995). In many cell types, caveolin-1 levels correlate with the degree of differentiation (Fan et al., 1983; P. Scherer et al., 1995; Song et al., 1996). Cells transformed by a variety of stimuli exhibit significantly decreased caveolin-1 levels, while caveolin-1 transfection into transformed cells results in a less malignant phenotype, suggesting a growth-regulating function (Koleske et al., 1995; Lee et al., 1998; Okamoto et al., 1998).

Caveolin-1 plays a central role in the regulation of cholesterol transport, mediating its efflux in fibroblasts (Murata et al., 1995; Uittenbogaard et al., 1998). The myelin sheath is particularly enriched in cholesterol, which appears to be synthesized by the SC themselves (Fu et al., 1998). Because myelinating SC have a much greater need for cholesterol biosynthesis than do dedifferentiated SC (Goodrum, 1990), which do not synthesize myelin, it is reasonable to speculate that myelinating SC require increased caveolin-1 expression for cholesterol homeostasis.

SC are an appealing cell type in which to study the relationship between caveolin-1 expression and cell phenotype, as SC will dedifferentiate and reenter the cell cycle after axotomy (S. Scherer and Salzer, 1996). Their dedifferentiation is accompanied by a decrease in the expression of myelin-related proteins and their cognate mRNAs. We have previously shown that myelinating SC in adult rat sciatic nerve (SN) express caveolin-1 (Mikol et al., 1999). In the present study, we explore caveolin-1 expression within the context of rat SC differentiation and dedifferentiation and find that its expression is tightly linked to the myelinating phenotype.

\section{MATERIALS AND METHODS Antibodies}

An affinity-purified rabbit antiserum against caveolin-1 (C13630), which recognizes both the $\alpha$ - and the $\beta$-isoforms of caveolin-1, was obtained from Transduction Laboratories (Lexington, KY). The anti-S-100 $\beta$ monoclonal antibody (mAb) was purchased from Sigma (St. Louis, MO; S-2532); an anti-p75 mAb was obtained from Calbiochem (La Jolla, CA; GR10); and the ED1 $\mathrm{mAb}$, which recognizes a lysosomal membrane protein of myeloid cells, particularly macrophages, was obtained from Serotec (Raleigh, NC). The anti- $\mathrm{P}_{0} \mathrm{mAb}$ and the anti-MAG antiserum were kindly provided by Drs. Juan Archelos (Max Planck Institute for Psychiatry, Munich, Germany) and James Salzer (New York University, New York), respectively.

\section{RT-PCR}

SC were isolated from postnatal day 3 (P3) SpragueDawley rats (Harlan-Sprague-Dawley, Indianapolis, IN), cultured on poly-L-lysine-coated plates, and maintained in Dulbecco's modified Eagle's medium (DMEM) with $10 \%$ fetal bovine serum (FBS), supplemented with $6 \mathrm{mM}$ L-glutamine, $2 \mu \mathrm{M}$ forskolin, and $10 \mu \mathrm{g} / \mathrm{ml}$ pituitary extract (Sigma) (Brockes et al., 1979; Porter et al., 1986). Cells were grown at $37^{\circ} \mathrm{C}$ in a humidified atmosphere with $10 \% \mathrm{CO}_{2}$ and grown to $\sim 80 \%$ confluency before cell lysates were collected. Total RNA was extracted from SC, using the guanidine isothiocyanate method (Chomczynski and Sacchi, 1987), and $2 \mu \mathrm{g}$ was used to synthesize cDNA with Superscript II (GibcoBRL Products, Gaithersburg, MD). Oligonucleotides used for reverse transcriptase-polymerase chain reaction (RT-PCR) were designed such that they fell within the $5^{\prime}$ and $3^{\prime}$ noncoding regions of the rat caveolin-1 cDNA (Accession no. Z46614) and were common to both the $\alpha$ - and $\beta$-isoforms. The oligonucleotide used for generation of template was CCTCCATCCCTGAAATGTCACTAT, and the primers used for subsequent PCR were CATAGGATCCAGAGCCTGCAGCCAGCCACG (5') and CATAGAATTCATCCCTGAAATGTCACTATATCT ( $\left.3^{\prime}\right)$, with internal BamHI and EcoRI restriction sites underlined, respectively, to facilitate cloning. For PCR amplification of cDNA template, high-fidelity Pfu polymerase (Stratagene, La Jolla, CA) was used. Product was restriction-digested with $B a m \mathrm{HI}$ and EcoRI (Boehringer-Mannheim, Indianapolis, IN), gelextracted, and then ligated into Bluescript vector (Stratagene) that had first been digested with $\mathrm{BamHI}$ and EcoRI. Clones were fully sequenced in both directions, using custom complementary primers and an automated DNA sequencer in the DNA Sequencing Core Facility at the University of Michigan.

\section{Immunoblotting}

SN was obtained from P1, P10, P35, and P90 Sprague-Dawley rats. In some cases, the perineurium was removed before homogenization. Nerves were disrupted with a Dounce homogenizer (6-8 strokes each, loose pestle followed by tight pestle) and then sonicated for three 10-s bursts. Protein was extracted using protease and phosphatase inhibitors (Mikol et al., 1999) and quantitated using a Protein Assay kit (Bio-Rad, Richmond, CA). SN lysates were analyzed by immunoblotting after sodium dodecyl sulfate-polyacrylamide electrophoresis (SDS-PAGE) and electrical transfer of proteins onto nitrocellulose (Mikol et al., 1999). Nitrocellulose sheets were probed with an affinity-purified rabbit antiserum against caveolin-1 (1:2,500), followed by peroxidase-conjugated secondary antibodies (1:2,500; Santa Cruz Biotechnology) and visualization by enhanced chemiluminescence (ECL). We similarly prepared immunoblots of normal SN and the distal stumps of lesioned adult rat SN (12 days post-transec- 


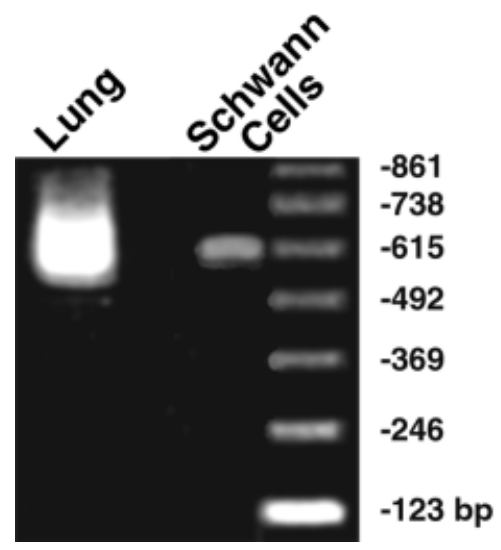

Fig. 1. Caveolin-1 mRNA expression. Reverse transcription-polymerase chain reaction (RT-PCR) (semiquantitative) of RNA from lung and Schwann cells (SC) yields a single product of $\sim 0.6 \mathrm{~kb}$ in each case. Caveolin-1 mRNA is more abundant in lung than in SC. A 123-bp DNA ladder is shown on the right.

tion). Identical blots were prepared and hybridized with rabbit antisera against caveolin-1 (1:2,500) or MAG (1:2,500). Positive and negative control lysates were immunoblotted along with SN lysates, and parallel immunoblots were incubated in the absence of primary antibody (conjugate controls).

\section{Immunohistochemistry}

SN were removed from P1, P6, P30, and P90 Sprague-Dawley rats and frozen in OCT compound (Ted Pella, Redding, CA). The distal stumps of adult nerves were similarly collected 12 days post-axotomy (transection). Sections were first fixed in $4 \%$ paraformaldehyde and then immunostained as previously described (Mikol et al., 1999). Antibodies against caveolin-1, S-100 $\beta$, ED1, and $\mathrm{P}_{0}$ were all used at 1:500. $\mathrm{Cy}-3$ - and fluorescein isothionate (FITC)-conjugated secondary antisera (Jackson Immunoresearch, Westgrove, PA) were used at 1:100. Conjugate controls were done in parallel. Slides were coverslipped and viewed by fluorescence microscopy using a Leitz fluorovert microscope (W. Nuhsbaum, McHenry, IL).

\section{RESULTS \\ Expression of Caveolin-1 in Developing Sciatic Nerve}

We demonstrated previously that caveolin-1 is present in rat SC, using affinity-purified antibodies (Mikol et al., 1999). To show that SC express caveolin-1 mRNA, we performed RT-PCR on RNA from cultured rat SC with the high-fidelity polymerase Pfu (Fig. 1). Upon sequencing two clones from two different RTPCR reactions, we obtained the identical sequence, which matches that for rat caveolin-1 $\alpha$ in the GenBank database (Accession no. Z46614), except for a
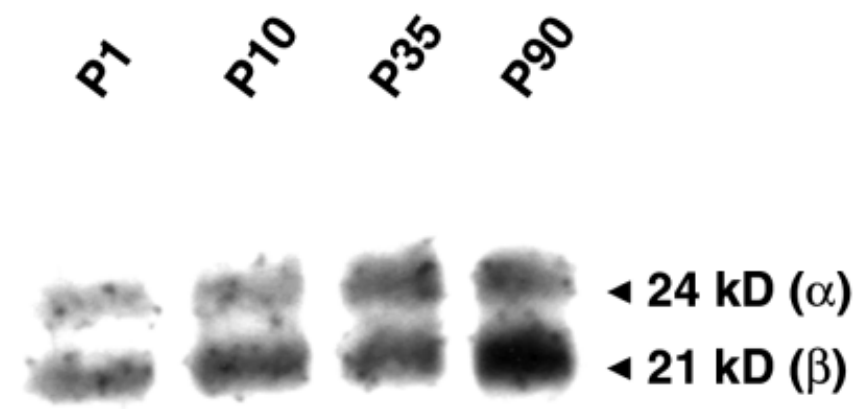

Fig. 2. Immunoblot analysis of caveolin-1 expression in developing sciatic nerve (SN). Lysates of whole rat SN obtained at P1, P10, P35, and P90 (40 $\mu \mathrm{g}$ each)were immunoblotted with an anti-caveolin-1 antiserum. Both caveolin-1 $\alpha(24 \mathrm{kDa})$ and $\beta(21 \mathrm{kDa})$ isoforms increase modestly during development.

single nucleotide difference $\left(\mathrm{G}_{387} \rightarrow \mathrm{C}\right)$ that would be predicted to cause a Gly $_{120} \rightarrow$ Ala substitution. This difference may represent a polymorphism, as we have cloned caveolin-1 from Sprague-Dawley rats, while the reported GenBank sequence was derived from a Norway rat. We detected only caveolin-1 $\alpha$ in cultured SC.

Because caveolin-1 expression increases during differentiation of many cell types (Fan et al., 1983; P. Scherer et al., 1995; Song et al., 1996), we wished to determine whether caveolin-1 expression by SC increases during myelination. Whereas the $8 \%$ acrylamide gels we previously used did not separate the two caveolin-1 isoforms, these were resolved on $12 \%$ gels. Immunoblot analysis of whole SN from P1, P10, P35, and P90 rats is shown in Figure 2.

Qualitatively, caveolin-1 content increases modestly at best during development; however, any change in SC-derived caveolin-1 could be obscured by the presence of substantial caveolin-1 from perineurium and blood vessels at all ages (Reale et al., 1975; Lisanti et al., 1994; Mikol et al., 1999).

Given these possible limitations of immunoblot analysis, we examined caveolin-1 expression by immunofluorescence. For this purpose, sections of rat SN obtained at ages similar to those used for immunoblotting were double-labeled for caveolin-1 and $\mathrm{P}_{0}$. This analysis was performed three times; the temporal progression of caveolin-1 expression and its spatial relationship to $\mathrm{P}_{0}$ are best illustrated in transverse sections (Fig. 3). At P1, caveolin-1 is expressed minimally within the endoneurium, but there is prominent staining of blood vessels and perineurium, which persists at all ages examined. $\mathrm{P}_{0}$ staining is relatively weak at $\mathrm{P} 1$, reflecting sparse myelination; $\mathrm{P}_{0}$ and caveolin-1 do not overlap. At P6, caveolin-1 expression by SC becomes apparent. In some instances, it closely opposes or surrounds the $\mathrm{P}_{0}$-positive myelin sheaths. Caveolin-1 staining of myelinating SC is widespread at P30, when myelination is essentially complete (Hahn et al., 1987). Between P30 and P90, we did not appreciate a change in either the amount of caveolin-1 expression or its localization in myelinating SC: caveolin-1 is present 

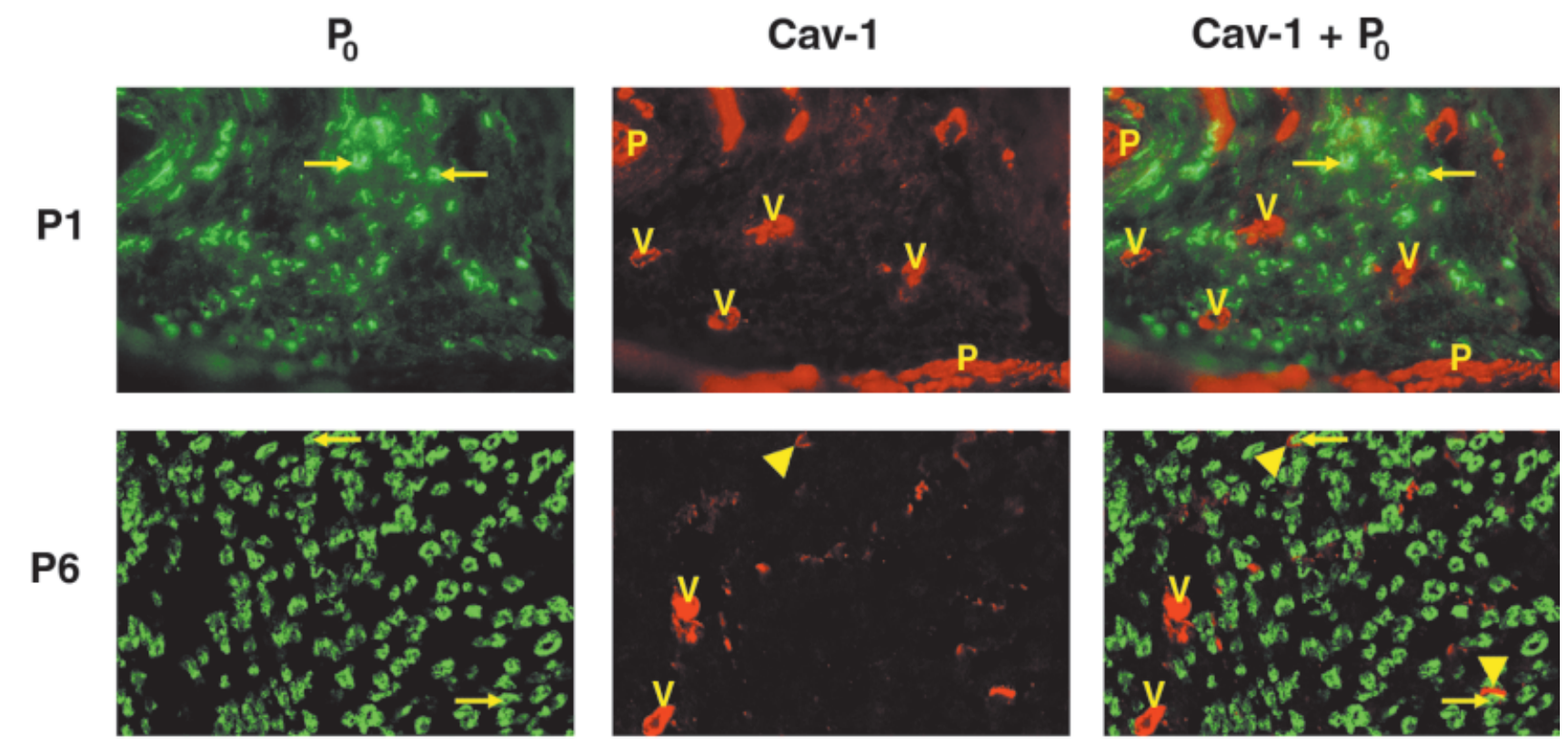

P30
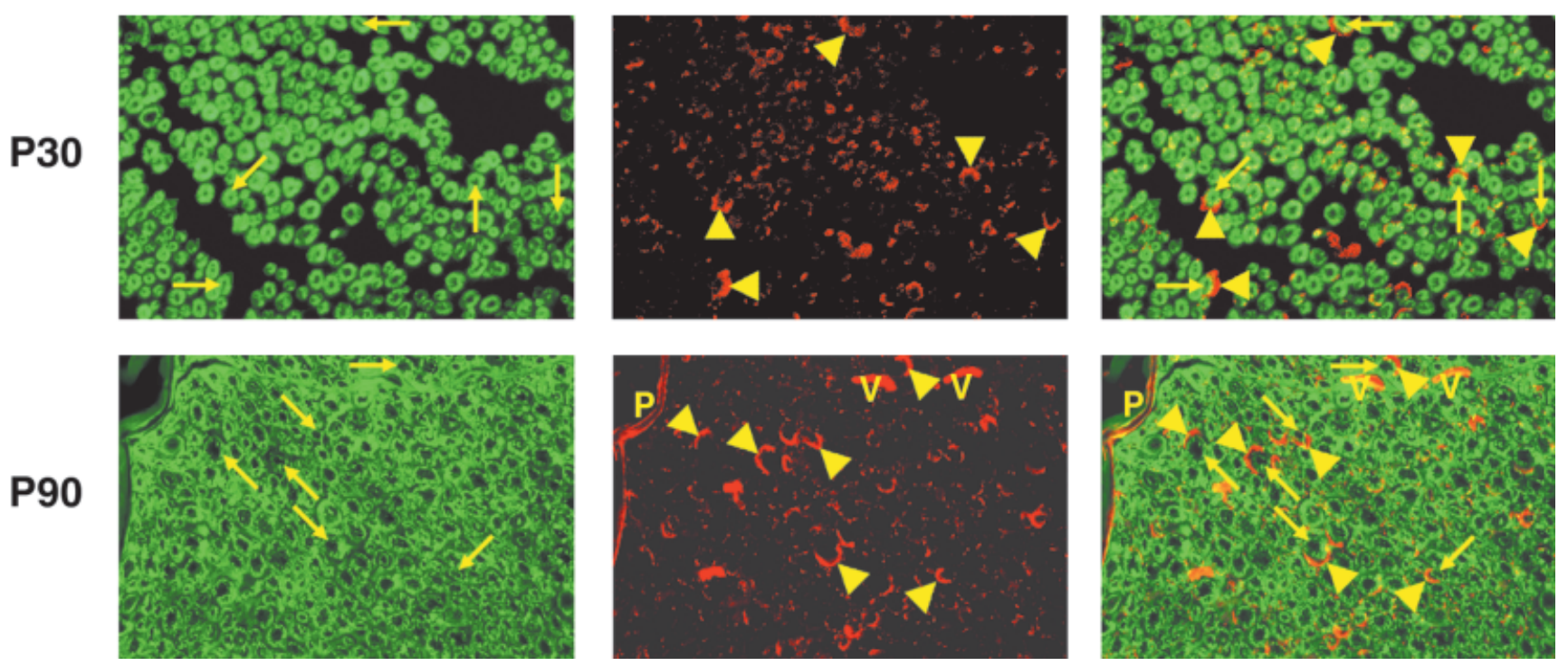

Fig. 3. Localization of caveolin-1 in developing sciatic nerve (SN). Transverse sections of P1 (A-C), P6 (D-F), P30 (G-I), and P90 $(\mathbf{J}-\mathbf{L})$ rat SN were double immunostained with a rabbit antiserum against caveolin-1 (B,E,H,K), an anti- $\mathrm{P}_{0}$ monoclonal antibody $(\mathrm{mAb})(\mathrm{A}, \mathrm{D}, \mathrm{G}, \mathrm{J})$, or both $(\mathrm{C}, \mathrm{F}, \mathrm{I}, \mathrm{L})$. At $\mathrm{P} 1$ and $\mathrm{P} 6$, caveolin- 1 is mainly localized to the endoneurial blood vessels (V) and perineurium $(\mathrm{P})$; the $\mathrm{P}_{0}$-positive myelin sheaths (arrows) are not stained. At P30 and P90, caveolin-1 localizes to the Schwann cell (SC) bodies and abaxonal membranes (arrowheads). Scale bar $=20 \mu \mathrm{M}$. largely in abaxonal membranes and in regions within the $\mathrm{SC}$ that surround $\mathrm{P}_{0}$-positive myelin sheaths.

\section{Expression of Caveolin-1 in Degenerating Nerve}

To investigate caveolin-1 expression in axotomized nerve, distal nerve stumps were collected 12 days after axotomy, because previous work has shown that at this time SC have largely reverted to a premyelinating phenotype (S. Scherer et al., 1995). We performed immunoblot analysis using perineurium-free $\mathrm{SN}$, hypothesizing that any change in SC caveolin-1 expression would be more apparent if the non-SC content of SN were minimized. Although one cannot remove the endoneurial blood vessels, much of the perineurium can be removed from adult SN. As shown in Figure 4, there is a clear decrease in the caveolin-1 content of perineurium-free SN after axotomy, especially regarding the $\alpha$-isoform; this finding was confirmed by performing the experiment three times. For comparison, we examined the level of MAG in normal and transected nerve by immunoblot analysis; as expected, MAG levels decrease after axotomy (Fig. 4).

Immunohistochemical analysis of transected nerve provides more dramatic results. As shown in Figure 5, 


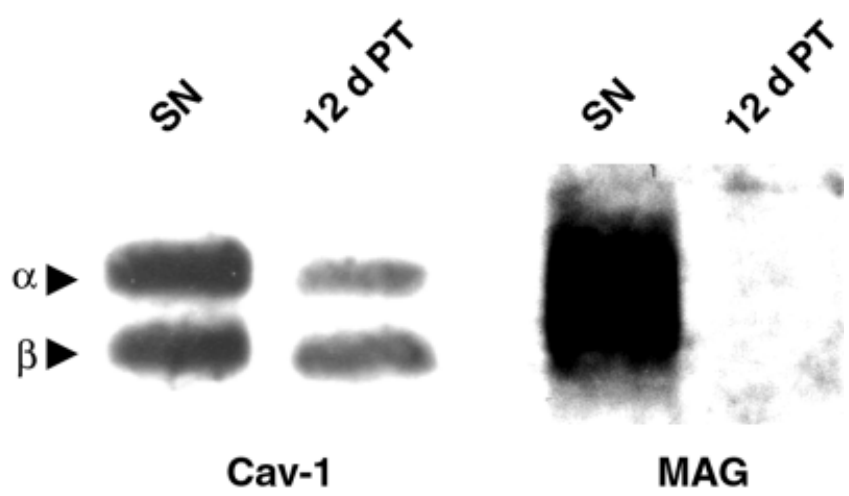

Fig. 4. Immunoblot analysis of perineurium-free sciatic nerve (SN). Lysates were prepared from an adult rat (P90) SN and an adult rat 12 days post-transection (12d PT); the nerves were stripped of perineurium to enrich for proteins expressed by Schwann cells. Two identical blots (using $40 \mu \mathrm{g}$ lysate per lane) were prepared and probed with rabbit antisera against caveolin-1 (Cav-1) and myelin-associated glycoprotein (MAG). Whereas the level of MAG $(\sim 100 \mathrm{kDa})$ is markedly decreased after axotomy, the level of caveolin- 1 is less diminished, especially the $\beta$-isoform. The experiment was performed three times with similar results.

12 days after axotomy, $\mathrm{P}_{0}$ is localized to the degenerating myelin sheaths, which are found in macrophages (Griffin et al., 1993). Caveolin-1 is also extremely reduced; the linear appearance of caveolin-1 immunoreactivity seen in longitudinal sections of normal nerve (Mikol et al., 1999) is absent. Some caveolin-1 staining colocalizes with $\mathrm{P}_{0}$-positive myelin debris, suggesting that it is localized in macrophages, which we directly confirmed by double-labeling sections for caveolin-1 and ED1, a marker of macrophages (Fig. 6). This caveolin-1 could have originated within the macrophages themselves (Matveev et al., 1999), or it could reflect residual caveolin-1 from phagocytosed myelinating $\mathrm{SCs}$, as previously noted for periaxin, a membraneassociated protein expressed by myelinating SCs (S. Scherer et al., 1995). It should be noted that there was no apparent change in caveolin-1 immunoreactivity of blood vessels and perineurium during development or after axotomy.

In further characterizing changes in caveolin-1 expression after axotomy, we compared caveolin-1 localization with that of $\mathrm{p} 75$. In adult rat SN, only nonmyelinating SC express p75 (Jessen and Mirsky, 1992; Jessen et al., 1994). However, in distal stumps obtained 12 days after transection, p75-positive "denervated" SC are numerous, allowing direct comparison between the expression patterns of caveolin- 1 and p75 (Fig. 5G,H). In all instances, p75-positive membranes are negative for caveolin-1-immunoreactivity. Thus, in contrast to myelinating SC, "denervated" SC do not express significant caveolin-1.

\section{DISCUSSION}

We have confirmed and extended our previous findings that SCs express caveolin-1 (Mikol et al., 1999).
We have cloned and sequenced caveolin-1 cDNA from cultured rat SC. Although immunoblot analysis demonstrates only a modest increase in caveolin-1 during postnatal development (owing to abundant caveolin-1 expression by blood vessels and perineurium), immunostaining demonstrates a progressive increase in caveolin-1 expression during myelination, slightly lagging $\mathrm{P}_{0}$ expression. Caveolin- 1 is localized to the outer/ abaxonal SC membrane and within SCs (surrounding compact myelin). After axotomy, residual caveolin-1 expression in axotomized nerve is mainly associated with myelin debris and macrophages.

\section{Myelinating SC Express Caveolin-1}

The above data document that caveolin-1 protein expression is fundamentally linked to the myelinating phenotype of SC. Caveolin-1 is found in myelinating SC, but not in premyelinating SC in early postnatal development or in denervated SC after nerve transection. This pattern of expression has been observed for many other myelin-related proteins, including $\mathrm{P}_{0}$, PMP22, MBP, MAG, connexin32, periaxin, $\beta 4$ integrin, and Egr-2/Krox20 (Feltri et al., 1994; S. Scherer and Asbury, 1993; S. Scherer et al., 1995; S. Scherer and Salzer, 1996; S. Scherer, 1997; Mirsky and Jessen, 1990, 1999; Jessen et al., 1999; Notterpek et al., 1999), and has been taken as evidence that (1) the protein plays an important role in myelinating SC; and (2) axon-SC interactions are required to maintain expression (S. Scherer et al., 1996).

\section{Caveolin-1 and Proliferation}

The expression of caveolin-1 expression in myelinating SC is consistent with the theme that its expression correlates with the level of cellular differentiation (Fan et al., 1983; P. Scherer et al., 1994, 1995; Mikol et al., 1999). For example, caveolin- 1 is induced 25 -fold when NIH 3T3-L1 fibroblasts differentiate into adipocytes, and in a variety of transformed cells its levels correlate inversely with the degree of oncogenic transformation and anchorage-independent growth (Koleske et al., 1995; Engelman et al., 1997; Lee et al., 1998). After a period of active proliferation of SC precursors during development, SC that associate with large axons cease dividing and form a myelin sheath (Jessen and Mirsky, 1991). After axotomy, SC revert to a precursor phenotype; i.e., they become $\mathrm{P}_{0}$-negative and $\mathrm{p} 75$-positive and reenter the cell cycle (Jessen and Mirsky, 1991, Jessen and Mirsky, 1992). Within this context, it may be relevant that caveolin-1 can suppress proliferation (Fielding et al., 1999; Bist et al., 2000). Caveolin-1 also modulates a variety of signal transduction pathways, largely functioning as a negative regulator of signal transduction. Caveolin-1 reduces signaling through the erbB2/neu receptor (Engelman et al., 1998b) and its downstream effectors, phosphatidylinositol 3-kinase 
A

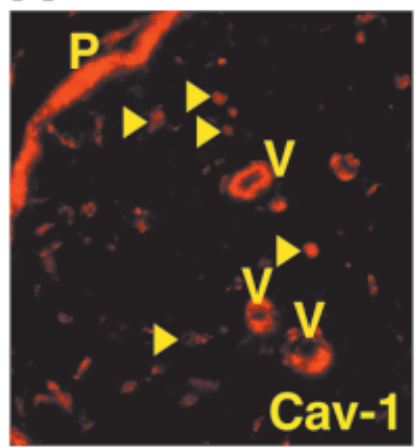

C

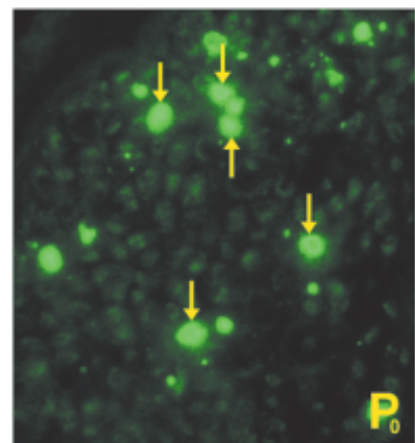

E

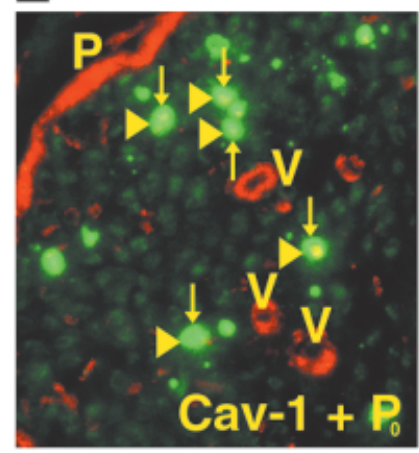

G

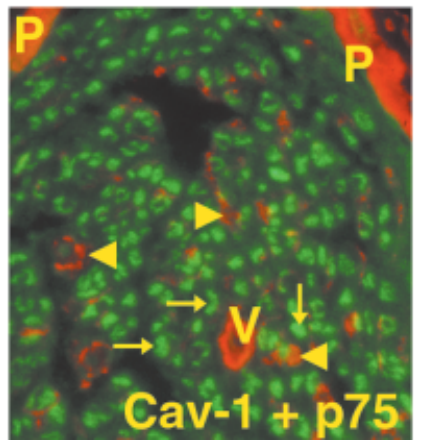

B

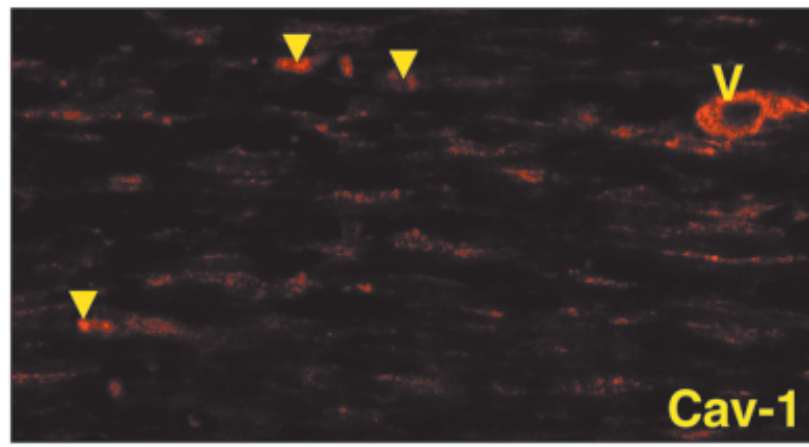

D

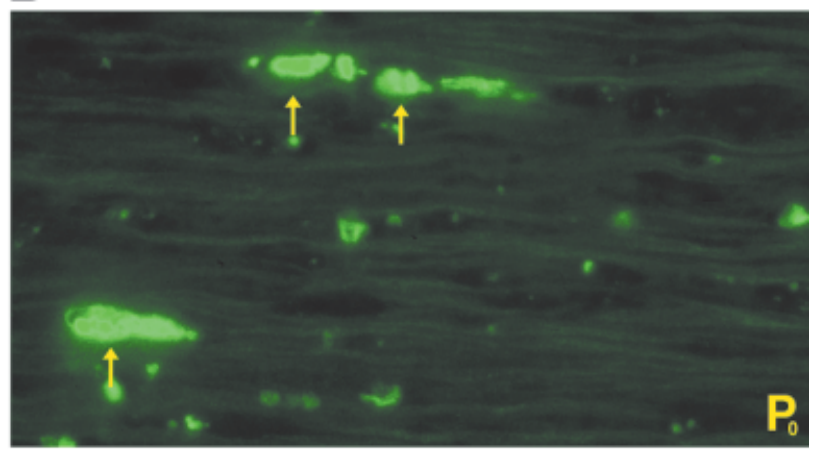

$\mathbf{F}$

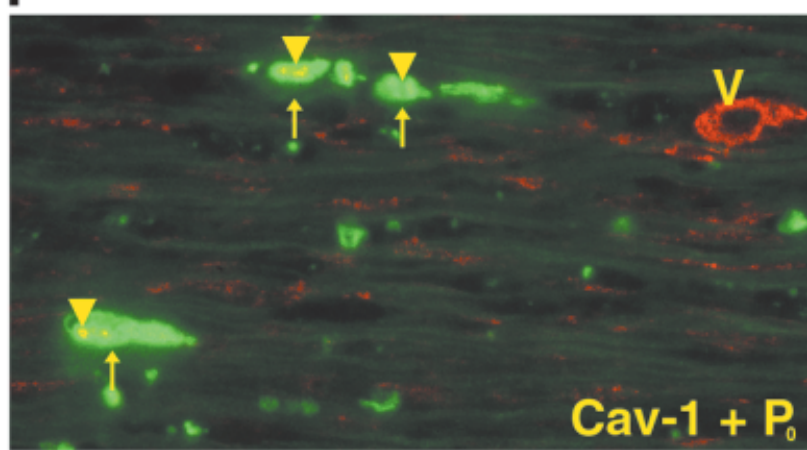

H

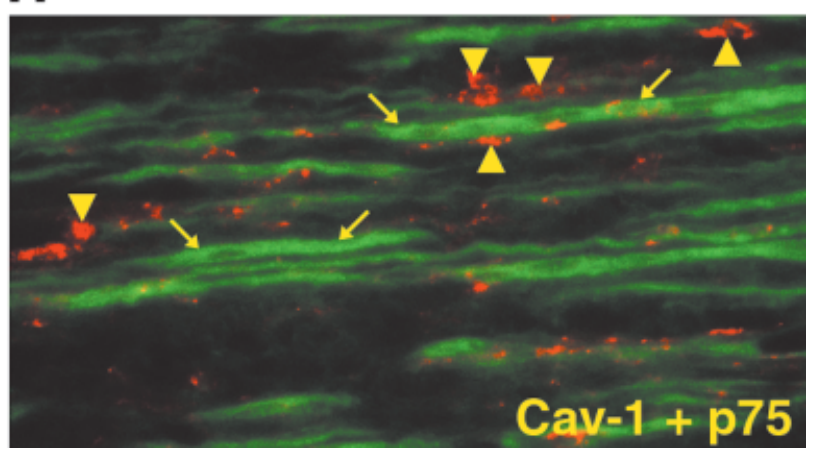

Fig. 5. Denervated Schwann cells (SCs) do not express caveolin-1. These are photomicrographs of transverse $(\mathbf{A}, \mathbf{C}, \mathbf{E}, \mathbf{G})$ and longitudinal $(\mathbf{B}, \mathbf{D}, \mathbf{F}, \mathbf{H})$ sections of rat sciatic nerve (SN) 12 days after axotomy, immunostained for either caveolin-1 (A,B), $\mathrm{P}_{0}(\mathbf{C}, \mathbf{D})$, caveolin-1 and $P_{0}(\mathbf{E}, \mathbf{F})$, or caveolin-1 and p75 $(\mathbf{G}, \mathbf{H})$. Compared with intact adult nerve (Fig. 3), caveolin-1 expression within the endoneurium is markedly decreased (arrowheads), and in some cases colocalizes with $\mathrm{P}_{0}$-positive myelin debris (arrows, A-F). In contrast, caveolin-1 immunoreactivity within perineurium $(\mathrm{P})$ and endoneurial blood vessels (V) remains intense. As $\mathbf{G}$ and $\mathbf{H}$ illustrate, caveolin-1 (arrowheads) and p75 (arrows) are not co-localized, indicating that denervated SC do not express caveolin-1. Scale bar = $20 \mu \mathrm{M}$.
(Zundel et al., 2000) and mitogen-activated protein kinase (Engelman et al., 1997, 1998a) activity, all of which have been implicated in proliferation and sur- vival of SC (Baek and Kim, 1998; Delaney et al., 1999; Cheng et al., 2000; Garratt et al., 2000; Maurel and Salzer, 2000). Thus, the loss of caveolin-1 expression by 
A

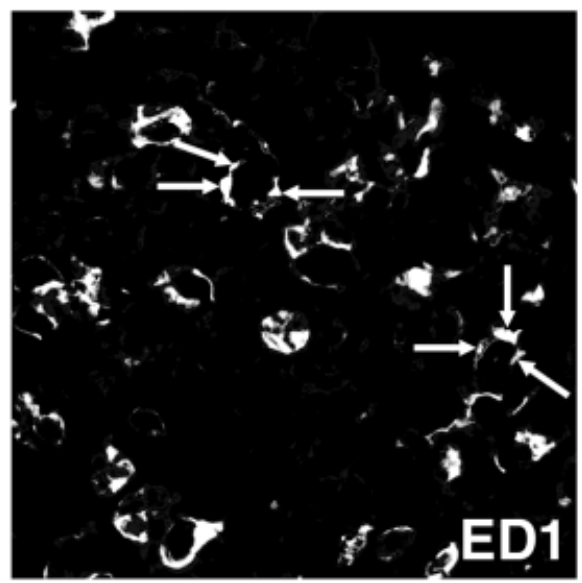

C

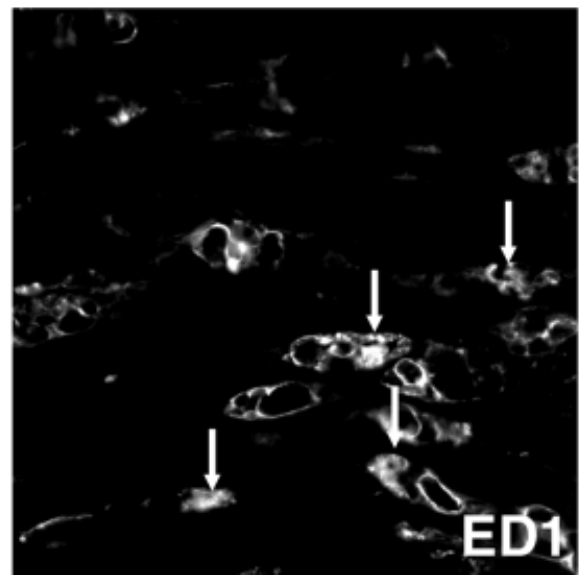

B

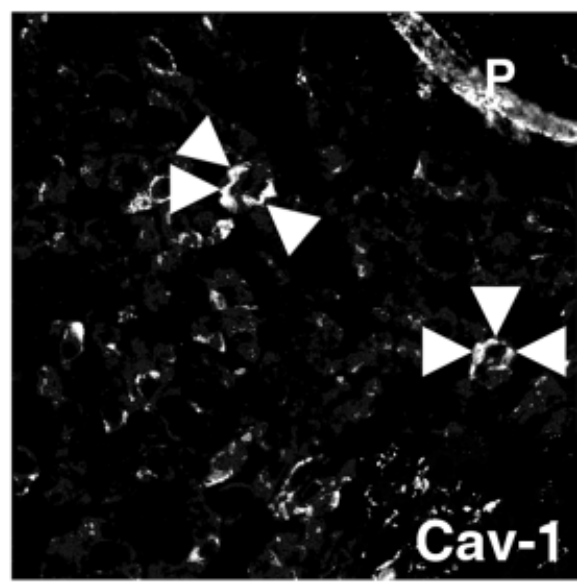

D

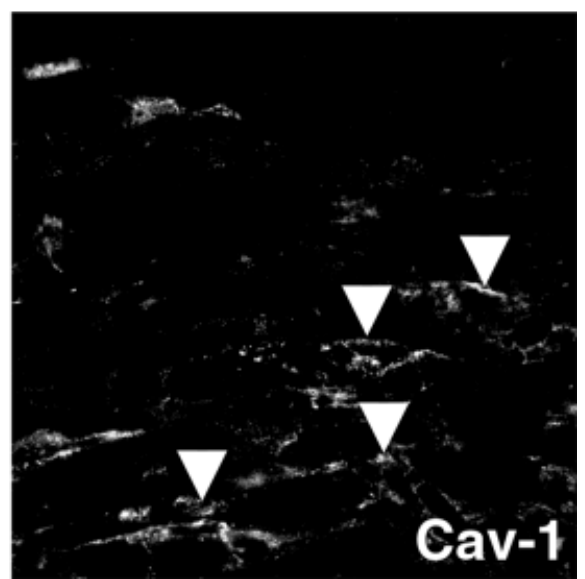

Fig. 6. Residual caveolin-1 is localized to macrophages. Photomicrographs of transverse (A,B) and longitudinal $(\mathbf{C , D})$ sections of rat sciatic nerve $(\mathrm{SN})$ 12 days after axotomy, immunostained with an ED1 mAb that recognizes macrophages $(\mathbf{A}, \mathbf{C})$ or rabbit antiserum against caveolin-1 $(B, D)$. Residual caveolin-1 (arrowheads) partially colocalizes with ED1 (arrows), indicative of macrophages that have infiltrated the nerve. Scale bar $=20 \mu \mathrm{M}$.
SC after axotomy may enable dedifferentiated SC to proliferate.

\section{Caveolin-1 and Cholesterol}

Another possible role of caveolin-1 in myelinating SC relates to the regulation of cholesterol transport. Cholesterol synthesis by SC increases during myelination and decreases when SC dedifferentiate (Goodrum, 1990). Caveolae are highly enriched in cholesterol (Simionescu et al., 1983), and the structure and function of caveolae are dependent on membrane cholesterol ( $\mathrm{Li}$ et al., 1996; Hailstones et al., 1998; Rothberg et al., 1990, 1992). Caveolin-1 itself is a cholesterolbinding protein (Murata et al., 1995), mediating cholesterol transport from the Golgi network to the plasma membrane in fibroblasts (Fielding et al., 1995, Fielding and Fielding, 1997) and cooperating with the highdensity lipoprotein-binding protein SR-B1 (which is enriched in caveolae) in maintaining cholesterol homeostasis (Matveev et al., 1999). While it is not yet clear what factors regulate caveolin-1 levels in SC, in non-neural cells cellular cholesterol concentration is critical. In fibroblasts, caveolin-1 expression varies inversely with the cellular free sterol level in order to facilitate cholesterol efflux as concentrations rise (Fielding et al., 1995, 1997; Fielding and Fielding, 1997); further, reciprocal changes in caveolin-1 and cholesterol have been identified during cell cycle progression (Fielding et al., 1999; Bist et al., 2000). Recent work has identified sterol regulatory element-like sequences and overlapping E2F- and Sp1-like sequences in the promoter region of caveolin-1 (Bist et al., 1997; Fu et al., 1998), the latter of which are known to have important effects in control of cell cycle regulation; deletion of this region abolishes cell cycle dependent changes in caveolin-1 expression (Fielding et al., 1999; Bist et al., 2000).

These findings are interesting in light of previous work that has shown that tellurium, an inhibitor of cholesterol biosynthesis at the squalene epoxidase step, causes reversible peripheral nerve demyelination in young rats, accompanied by downregulation of my- 
elin proteins, upregulation of $\mathrm{p} 75$, and SC proliferation, as SC revert to a precursor phenotype (WagnerRecio et al., 1991; Toews et al., 1992). The rather selective toxicity to peripheral nerve has been attributed to the relative demands for cholesterol synthesis, with myelin synthesis proceeding rapidly in the peripheral nerves of weanling rats. It has been assumed that the demyelinating effect of cholesterol lowering in myelinating SC is direct, i.e., caused by structural factors, although an intriguing possibility is that cholesterol lowering results in decreased caveolin-1 expression, SC dedifferentiation and proliferation, and subsequent demyelination. Given that caveolin-1 and cholesterol may together regulate cell cycle regulation, caveolin-1 upregulation in myelinating SC is consistent with its potential role in differentiation and cholesterol transport, while its downregulation in the setting of demyelination may enable dedifferentiation and cell proliferation. To our knowledge, caveolin-1 expression has not been studied in the tellurium model of demyelination.

Compelling evidence for a link between cellular cholesterol homeostasis and caveolin expression in vivo comes from research on Niemann-Pick type C (NPC) disease, which in humans causes a progressive demyelinating disorder. Mutations in the murine NPC gene lead to altered expression of NPC1, a membrane protein that has a cholesterol-sensing domain (Garver et al., 1997). Homozygotes lacking NPC1 exhibit greatly increased free cholesterol levels and a slight increase in caveolin-1 expression, while heterozygotes show near-normal cholesterol levels but greatly increased caveolin-1, the latter presumably reflecting a compensatory response to maintain cholesterol balance that homozygotes are not able to withstand in light of significantly elevated free cholesterol and absent NPC1.

Taken together with our data, these findings suggest an intimate connection between caveolin-1 expression and SC phenotype. We hypothesize that caveolin-1 plays an important role in myelinating $\mathrm{SC}$, such as regulation of signal transduction, cell cycle control, and growth regulation and/or cholesterol transport. Future work will investigate the molecular mechanisms whereby caveolin-1 modulates SC phenotype.

\section{ACKNOWLEDGMENTS}

The authors thank Judith Boldt for secretarial assistance, Susun Kim and Ted Xu for technical assistance, and Drs. James Salzer and Juan Archelos for their generous gifts of antibodies. This work was supported by the National Institutes of Health, grants NS01928 (to D.D.M.), NS08075 and NS37100 (to S.S.S.), NS36778 and NS38849 (to E.L.F.), the Juvenile Diabetes Research Foundation (to S.S.S. and E.L.F.), and the American Diabetes Association (to E.L.F.).

\section{REFERENCES}

Baek SY, Kim SU. 1998. Proliferation of human Schwann cells induced by neu differentiation factor isoforms. Dev Neurosci 20:512517.

Bist A, Fielding PE, Fielding CJ. 1997. Two sterol regulatory elementlike sequences mediate up-regulation of caveolin gene transcription in response to low density lipoprotein free cholesterol. Proc Natl Acad Sci U S A 94:10693-10698.

Bist A, Fielding CJ, Fielding PE. 2000. p53 regulates caveolin gene transcription, cell cholesterol, and growth by a novel mechanism. Biochemistry 39:1966-1972.

Brockes JP, Fields KL, Raff MC. 1979. Studies on cultured rat Schwann cells. I. Establishment of purified populations from cultures of peripheral nerve. Brain Res 165:105-118.

Cheng H-L, Steinway M, Russell JW, Feldman EL. 2000. GTPases and phosphatidylinositol-3 kinase are critical for insulin-like growth factor-I mediated Schwann cell motility. J Biol Chem 275: 27197-27204.

Chomczynski P, Sacchi N. 1987. Single-step method of RNA isolation by acid guanidinium thiocyanate-phenol-chloroform extraction. Anal Biochem 162:156-159.

Delaney CL, Cheng H-L, Feldman EL. 1999. Insulin-like growth factor-I prevents caspase mediated apoptosis in Schwann cells. J Neurobiol 41:540-548.

Engelman JA, Wykoff CC, Yasuhara S, Song KS, Okamoto T, Lisanti MP. 1997. Recombinant expression of caveolin-1 in oncogenically transformed cells abrogates anchorage-independent growth. J Biol Chem 272:16374-16381.

Engelman JA, Chu C, Lin A, Jo H, Ikezu T, Okamoto T, Kohtz DS, Lisanti MP. 1998a. Caveolin-mediated regulation of signaling along the p42/44 MAP kinase cascade in vivo. FEBS Lett 428:205-211.

Engelman JA, Lee RJ, Karnezis A, Bearss DJ, Webster M, Siegel P, Muller WJ, Windle JJ, Pestell RG, Lisanti MP. 1998b. Reciprocal regulation of neu tyrosine kinase activity and caveolin-1 protein expression in vitro and in vivo. J Biol Chem 273:20448-20455.

Fan JY, Carpentier J-L, Van Obberghen E, Grunfeld C, Gorden P, Orci L. 1983. Morphological changes of the 3T3-L1 fibroblast plasma membrane upon differentiation to the adipocyte form. J Cell Sci 61:219-230.

Feltri ML, Scherer SS, Nemni R, Kamholz J, Vogelbacker H, Scott MO, Canal N, Quaranta V, Wrabetz L. 1994. $\beta_{4}$ integrin expression in myelinating Schwann cells is polarized, developmentally regulated and axonally dependent. Development 120:1287-1301.

Fielding CJ, Fielding PE. 1997. Intracellular cholesterol transport. J Lipid Res 38:1503-1521.

Fielding CJ, Bist A, Fielding PE. 1997. Caveolin mRNA levels are up-regulated by free cholesterol and down-regulated by oxysterols in fibroblast monolayers. Proc Natl Acad Sci U S A 94:3753-3758.

Fielding CJ, Bist A, Fielding PE. 1999. Intracellular cholesterol transport in synchronized human skin fibroblasts. Biochemistry 38:2506-2513.

Fra AM, Williamson E, Simons K, Parton RG. 1995. De novo formation of caveolae in lymphocytes by expression of VIP21-caveolin. Proc Natl Acad Sci U S A 92:8655-8659.

Fu Q, Goodrum JF, Hayes C, Hostettler JD, Toews AD, Morell P. 1998. Control of cholesterol biosynthesis in Schwann cells. J Neurochem 71:549-555.

Garratt AN, Voiculescu O, Topilko P, Charnay P, Birchmeier C. 2000. A dual role of erbB2 in myelination and in expansion of the Schwann cell precursor pool. J Cell Biol 148:1035-1046.

Garver WS, Erickson RP, Wilson JM, Colton TL, Hossain GS, Kozloski MA, Heidenreich RA. 1997. Altered expression of caveolin-1 and increased cholesterol in detergent insoluble membrane fractions from liver in mice with Niemann-Pick disease type C. Biochim Biophys Acta 1361:272-280.

Glenney JR, Soppet D. 1992. Sequence and expression of caveolin, a protein component of caveolae plasma membrane domains phosphorylated on tyrosine in Rous sarcoma virus-transformed fibroblasts. Proc Natl Acad Sci U S A 89:10517-10521.

Goodrum JF. 1990. Cholesterol synthesis is down-regulated during regeneration of peripheral nerve. J Neurochem 54:1709-1715.

Griffin JW, Kidd G, Trapp BD. 1993. Interactions between axons and Schwann cells. In: Dyck PJ, Thomas PK, Griffin JW, Low PA, Poduslo JF, editors. Peripheral neuropathy. Philadelphia: WB Saunders. p 317-330.

Hahn AF, Chang Y, Webster HD. 1987. Development of myelinated nerve fibers in the sixth cranial nerve of the rat: a quantitative electron microscope study. J Comp Neurol 260:491-500. 
Hailstones D, Sleer LS, Parton RG, Stanley KK. 1998. Regulation of caveolin and caveolae by cholesterol in MDCK cells. J Lipid Res 39:369-379.

Jessen KR, Mirsky R. 1991. Schwann cell precursors and their development. Glia 4:185-194.

Jessen KR, Mirsky R. 1992. Schwann cells: early lineage, regulation of proliferation and control of myelin formation. Curr Opin Neurobiol 2:575-581.

Jessen KR, Mirsky R. 1999a. Developmental regulation in the Schwann cell lineage. Adv Exp Med Biol 468:3-12.

Jessen KR, Mirsky R. 1999b. Why do Schwann cells survive in the absence of axons? Ann NY Acad Sci 883:109-115.

Jessen KR, Mirsky R, Morgan L. 1991. Role of cyclic AMP and proliferation controls in Schwann cell differentiation. Ann NY Acad Sci 633:78-89.

Jessen KR, Brennan A, Morgan L, Mirsky R, Kent A, Hashimoto Y, Gavrilovic J. 1994. The Schwann cell precursor and its fate: a study of cell death and differentiation during gliogenesis in rat embryonic nerves. Neuron 12:509-527.

Kogo H, Fujimoto T. 2000. Caveolin-1 isoforms are encoded by distinct mRNAs. Identification of mouse caveolin-1 mRNA variants caused by alternative transcription initiation and splicing. FEBS Lett 465: $119-123$.

Koleske AJ, Baltimore D, Lisanti MP. 1995. Reduction of caveolin and caveolae in oncogenically transformed cells. Proc Natl Acad Sci U S A 92:1381-1385.

Lee SW, Reimer CL, Oh P, Campbell DB, Schnitzer JE. 1998. Tumor cell growth inhibition by caveolin re-expression in human breast cancer cells. Oncogene 16:1391-1397.

Li S, Song KS, Lisanti MP. 1996. Expression and characterization of recombinant caveolin. J Biol Chem 271:568-573.

Lisanti MP, Tang ZL, Sargiacomo M. 1993. Caveolin forms a heterooligomeric protein complex that interacts with an apical GPI-linked protein: implications for the biogenesis of caveolae. J Cell Biol 123:595-604.

Lisanti MP, Scherer PE, Vicugiriene J, Tang Z-L, Hermanowski M, Vosatka A, Tu Y-H, Cook RF, Sargiacomo M. 1994. Characterization of caveolin-rich membrane domains isolated from an endothelial-rich source: implications for human disease. J Cell Biol 126: $111-126$.

Matveev S, van der Westhuyzen DR, Smart EJ. 1999. Co-expression of scavenger receptor-BI and caveolin-1 is associated with enhanced selective cholesteryl ester uptake in THP-1 macrophages. J Lipid Res 40:1647-1654.

Maurel P, Salzer JL. 2000. Axonal regulation of Schwann cell proliferation and survival and the initial events of myelination requires PI 3-kinase activity. J Neurosci 20:4635-4645.

Mikol DD, Hong H, Cheng H-L, Feldman EL. 1999. Caveolin-1 expression in Schwann cells. Glia 27:39-52.

Mirsky R, Jessen KR. 1990. Schwann cell development and the regulation of myelination. Semin Neurosci 2:423-435.

Mirsky R, Jessen KR. 1999. The neurobiology of Schwann cells. Brain Pathol 9:293-311.

Murata M, Peranen J, Schreiner R, Wieland F, Kurzchalia TV, Simons K. 1995. VIP21/caveolin is a cholesterol-binding protein. Proc Natl Acad Sci U S A 92:10339-10343.

Notterpek L, Snipes GJ, Shooter EM. 1999. Temporal expression pattern of peripheral myelin protein 22 during in vivo and in vitro myelination. Glia 25:358-369.

Okamoto T, Schlegel A, Scherer PE, Lisanti MP. 1998. Caveolins, a family of scaffolding proteins for organizing "preassembled signaling complexes" at the plasma membrane. J Biol Chem 273:54195422.

Porter S, Clark MB, Glaser L, Bunge RP. 1986. Schwann cells stimulated to proliferate in the absence of neurons retain full functional capability. J Neurosci 6:3070-3078.

Reale E, Luciano L, Spitznas M. 1975. Freeze-fracture faces of the perineurial sheath of the rabbit sciatic nerve. J Neurocytol 4:261270 .
Rothberg KG, Ying Y, Kamen BA, Anderson RGW. 1990. Cholesterol controls the clustering of the glycophospholipid-anchored membrane receptor for 5-methyltetrahydrofolate. J Cell Biol 111:29312938.

Rothberg KG, Heuser JE, Donzell WC, Ying Y, Glenney JR, Anderson RGW. 1992. Caveolin, a protein component of caveolae membrane coats. Cell 68:673-682.

Sargiacomo M, Scherer PE, Tang Z, Kubler E, Song KS, Sanders MC, Lisanti MP. 1995. Oligomeric structure of caveolin: implications for caveolae membrane organization. Proc Natl Acad Sci U S A 92: 9407-9411.

Scherer PE, Lisanti MP, Baldini G, Sargiacomo M, Corley Mastick C, Lodish HF. 1994. Induction of caveolin during adipogenesis and association of GLUT4 with caveolin-rich vesicles. J Cell Biol 127: 1233-1243.

Scherer PE, Tang Z, Chun M, Sargiacomo M, Lodish HF, Lisanti MP. 1995. Caveolin isoforms differ in their N-terminal protein sequence and subcellular distribution. J Biol Chem 270:16395-16401.

Scherer PE, Okamoto T, Chun M, Nishimoto I, Lodish HF, Lisanti MP. 1996. Identification, sequence, and expression of caveolin-2 defines a caveolin gene family. Proc Natl Acad Sci U S A 93:131135 .

Scherer SS. 1997. The biology and pathobiology of Schwann cells. Curr Opin Neurol 10:386-397.

Scherer SS, Asbury AK. 1993. Inherited axonal neuropathies. In: Rosenberg RN, Prusiner SB, DiMauro S, Barchi RL, Kunkle LM, editors. The molecular and genetic basis of neurological disease. Woburn, MA: Butterworth-Heinemann. p 899-921.

Scherer SS, Salzer JL. 1996. Axon-Schwann cell interactions during peripheral nerve degeneration and regeneration. In: Jessen KR, Richardson WD, editors. Glial cell development. Oxford: BIOS Scientific. p 165-196.

Scherer SS, Deschenes SM, Xu Y, Grinspan JB, Fischbeck KH, Paul DL. 1995a. Connexin32 is a myelin-related protein in the PNS and CNS. J Neurosci 15:8281-8294.

Scherer SS, Xu YT, Bannerman PG, Sherman DL, Brophy PJ. 1995b. Periaxin expression in myelinating Schwann cells: modulation by axon-glial interactions and polarized localization during development. Development 121:4265-4273.

Simionescu N, Lupu F, Simionescu M. 1983. Rings of membrane sterols surround the openings of vesicles and fenestrae, in capillary endothelium. J Cell Biol 97:1592-1600.

Song KS, Scherer PE, Tang Z, Okamoto T, Li S, Chafel M, Chu C, Kohtz DS, Lisanti MP. 1996. Expression of caveolin-3 in skeletal, cardiac, and smooth muscle cells. J Biol Chem 271:15160-15165.

Tang Z, Scherer PE, Okamoto T, Song K, Chu C, Kohtz DS, Nishimoto I, Lodish HF, Lisanti MP. 1996. Molecular cloning of caveolin-3, a novel member of the caveolin gene family expressed predominantly in muscle. J Biol Chem 271:2255-2261.

Taniuchi M, Clark HB, Johnson EM. 1986. Induction of nerve growth factor receptor in Schwann cells after axotomy. Proc Natl Acad Sci U S A 83:4094-4098.

Toews AD, Griffiths IR, Kyriakides E, Goodrum JF, Eckermann CE, Morell P, Thomson CE. 1992. Primary demyelination induced by exposure to tellurium alters Schwann cell gene expression: a model for intracellular targeting of NGF receptor. J Neurosci 12:36763687.

Uittenbogaard A, Ying Y, Smart EJ. 1998. Characterization of a cytosolic heat-shock protein-caveolin chaperone complex. J Biol Chem 273:6525-6532.

Wagner-Recio M, Toews AD, Morell P. 1991. Tellurium blocks cholesterol synthesis by inhibiting squalene metabolism: preferential vulnerability to this metabolic block leads to peripheral nervous system demyelination. J Neurochem 57:1891-1901.

Webster H. 1993. Development of peripheral nerve fibers. In: Dyck PJ, Thomas PK, Griffin JW, Low PA, Podulso JF, editors. Peripheral neuropathy. Philadelphia: WB Saunders. p 243-266.

Zundel W, Swiersz LM, Giaccia A. 2000. Caveolin 1-mediated regulation of receptor tyrosine kinase-associated phosphatidylinositol 3-kinase activity by ceramide. Mol Cell Biol 20:1507-1514. 